\title{
Assessing Practice Habits: A Study of Collegiate Instrumental Teachers' Estimation of Students' Practice Habits Versus Students' Self-Report
}

\author{
Lau Chooi Wee \\ College of Music, Mahidol University, Thailand \\ Phutthamonthon Nakhonpathom, 73170 Thailand \\ e-mail: chooiwee@ hotmail.com \\ *Corresponding author: chooiwee@ hotmail.com
}

Published: 26 August 2020

Cite this article (APA): Lau, C.W. (2020). Assessing practice habits: A study of collegiate instrumental teachers' estimation of students' practice habits versus students' self-report, Malaysian Journal of Music, 9, 17-28. https://doi.org/10.37134/mjm.vol9.2.2020

\begin{abstract}
This survey research aims to assess the collegiate instrumental teachers' ability to estimate students' practice habits in the practice room based on the students' performance during the instrumental lesson and to collect collegiate instrumental teachers' suggestions on estimating students' practice habits in the practice room. A questionnaire in two forms was designed for 15 collegiate instrumental teachers and 30 music performance undergraduate students who were selected through a convenience sampling approach. The percent agreement $\left(\mathrm{P}_{\mathrm{A}}\right)$ and Cohen's kappa $(\kappa)$ were utilised to examine the inter-rater reliability between the results of both participants on the practice habits that focus on the practice time, practice sessions, goal setting, focused attention, mental practice, technique practice, metronome practice, practise with an electronic tuner, and practise with other practice strategies. The low average results, $31.50 \%$ on the percent agreement and .0437 on the Cohen's kappa revealed that collegiate instrumental teachers cannot effectively estimate their students' practice habits in the practice room based on the students' performance during the instrumental lesson. However, an interesting observation was made from the suggestions given by the teachers, that is, the importance of communication of practice habits as well as observation of them in the private lesson studio. To improve, a system that teaches the key indicators of estimating students' practice habits or a training package or method to observe students' use of practice habits in the practice room is recommended to develop for future teachers.
\end{abstract}

Keywords: collegiate instrumental teacher, estimation, instrumental lesson, music practice, practice habits

\section{Background}

Music teachers listen to students' performance during their weekly instrumental lessons and provide guidance and formative feedback to improve students' playing ability and technique. Students are expected to practise and demonstrate some improvements in the following lesson (Kostka, 2002). However, the results of the practice are not always as expected. Some students showed significant improvements after a week of practice, but others' playing remains relatively unchanged week after week although they claimed that they did practice (Pike, 2014). As teachers cannot observe how their students practice in the practice room, it is possible to estimate the students' practice habits based on the performance during the weekly instrumental lessons and then provide feedback or develop suitable practice strategies for the students to improve their skills (Pike, 2014; Scott, 2012).

Some music teachers think that they can estimate their students' practice habits correctly based on their teaching and learning experience, although their prediction might sometimes be inaccurate. Mills (2007) realised that her teacher could not tell whether she had practised during the week due to 
the false estimation of her teacher. She mentioned that sometimes she had spent more time practising but her teacher thought she had not practise, whereas the teacher occasionally praised her for a good performance when she had not put in any effort in her practice. An example of false estimation like this can cause serious consequences for both teachers and students. Teachers' competence will be questioned and what they said will sound unconvincing while students will feel frustrated and unmotivated with the comments they received.

There is little information written on the teachers' ability to effectively estimate students' practice habits in the practice room during the weekly instrumental lessons. The only information was from Conrad (2012), who discussed 10 clues for music teachers to detect during music lessons when a student had not practised. However, the clues provided were general and the method to estimate students' practice habits in the practice room had not been included. Therefore, this study aims to i) assess the collegiate instrumental teachers' ability to estimate students' practice habits in the practice room based on the students' performance during the instrumental lesson, and ii) collect collegiate instrumental teachers' suggestions on estimating students' practice habits in the practice room.

This is the first study to clarify the instrumental teachers' ability to estimate students' practice habits in the practice room during the instrumental lesson. This study attempts to create a sense of awareness to all experienced and non-experienced instrumental teachers on the importance of estimating the students' practice habits in the practice room accurately during the weekly instrumental lessons since there is a lack of attention, information, and training on this topic.

\section{Literature Review}

Practice habits in this study imply practice time, practice sessions, and a series of practice behaviour that was used to achieve mastery and fluency while rehearsing or performing a musical instrument. The word, 'practice', is defined as "repeated performance or systematic exercise for the purpose of learning or acquiring proficiency" (Barry \& Hallam, 2002, p. 151), while 'habit' is the repetition of the practice behaviour that can be developed through three elements of habit loop: The cue, the trigger of repeating action; The behaviour, the routine that one exhibits; and The reward, the motivator to continue the behaviour in the future. One can cultivate a habit triggered by a goal but eventually it will become an automatic action without being conscious (Duhigg, 2012; Neal et al., 2006).

Research indicates that music experts require a period of 10 or more years of preparation to develop and refine their skills to the mastery level (Ericsson et al., 1993). Besides, the daily practice schedule was suggested to college music majors. Schuring (2009) proposed that college music majors should practise three to five hours daily, with five hours as maximum to prevent body and mind exhaustion. One should spend a minimum of forty-minutes on warming up and at least ninety-minutes to maintain the progress of the work. The more the time can be extended, the more improvement will take place in practice. Schuring (2009) also suggested to split the practice time into several sessions per day, take a break for each practice hour, and try to practise just before (for warming up and reviewing repertoire for the lesson) and just after (for revision and reviewing new knowledge) the weekly instrumental lessons. Although the time spent on practising is important, it is not a decisive factor for musical achievement (Madsen, 2004; Miksza, 2007). Practice must be deliberate, informed, and 'mindful' in order to be useful. According to Madsen (2004), 89\% of the respondents believed that their performance achievement was closely associated with the total amount of deliberative practice. Also, results in Platz et al. (2014) showed that long-term deliberate practice is the fundamental for attaining expert performance in music.

Many articles discussed effective practice habits in instrumental practice. Among them, Bynum (2019) stated that the best way to produce productive practice habits on trombone playing was to keep the practice consistent, goal-oriented, simple, and positive. Besides, Johnson (2009) thought that practice would become effective when it was goal-oriented, multifaceted, when it included a variety of problem-solving strategies, and when it involved reflection or self-evaluation. Also, in an article written by Miksza and Tan (2015), five categories of practice processes were suggested by the faculty studio teachers and collegiate music students in an open-ended questionnaire: i) analyse the music and prioritise goals before practice, ii) decide which practice strategies or techniques to execute, iii) form positive habits, iv) self-evaluate during and after practising, and v) perform as a concluding activity. 
The repetition of these practice processes is believed to be able to form positive or good practice habits during the practice sessions. However, there is no information to discuss music teachers' ability to estimate students' practice habits in the practice room based on the observations during the weekly instrumental lessons and to suggest how practice habits in the practice room could be observed. Thus, this study aims to serve these purposes.

\section{Methodology}

\section{Participants}

Two groups of participants were selected through the convenience sampling approach in one of the music colleges in Thailand. First, 15 collegiate instrumental teachers. Among 29 faculty members from the Strings and Chamber Music Department, Woodwinds Department, and Brass and Percussion Department of the music college that participated, only 15 of them were recruited as they fulfilled all the requirements set. The requirements include an instrumental teacher who plays classical music, whose major instrument is a string, woodwind or brass instrument, and who is keen on participating in the study. Besides this, each of them has to have at least two music performance undergraduate students and hold a Master's or Doctoral degree in the music-related field. The background information of the collegiate instrumental teacher is summarised as follows.

Gender. 14 male teachers (93.33\%) and one female teacher (6.67\%) among the 15 teacher participants.

Nationality. Five teachers (33.33\%) from the United States, two teachers each (13.33\%) from Poland, Latvia, and Thailand, and one teacher each (6.67\%) from Greece, Germany, Japan, and the Republic of China (Taiwan). These teachers are full-time faculties from the music college that was participated.

Teaching qualifications. 10 teachers (66.67\%) that hold a Master's degree in performance, performance and pedagogy, or performance and chamber music, and five teachers (33.33\%) that hold a doctoral degree in performance, or performance and pedagogy.

Years of teaching experience. Five teachers (33.33\%) have 11-15 years of experience teaching at the university level, followed by four teachers (26.67\%) with 16-20 years, three teachers (20\%) with 6-10 years, 2 teachers (13.33\%) with 1-5 years, and one teacher (6.67\%) with $21-25$ years of experience teaching at the university level.

The second group of participants consist of 30 music performance undergraduate students, formed by two students recruited from each collegiate instrumental teacher mentioned above, who play classical music, whose major instruments are strings, woodwind or brass instruments, and who agreed to take part in the study. Again, background information for the music performance undergraduate students was summarised and listed below.

Gender. 19 male students (63.33\%) and 11 female students (36.67\%) involved in this study that makes up a total of 30 students.

Nationality. Among the 30 students, 27 students (90\%) are from Thailand, two students (6.67\%) from China, and one student (3.33\%) from South Korea.

Academic years in music performance undergraduate program. Nine first- and third-year students (30\% each), seven second-year students (23.33\%), and five fourth-year (16.67\%) music performance undergraduate students were involved in this study. 
Only a limited number of participants who met the requirements took part in this study. However, according to Bujang and Baharum (2017), Cohen's kappa "minimum required sample size is proposed from more than 10 to less than 30" (p. 9). Therefore, the number of participants in this study is relevant to the inter-rater reliability results.

\section{Questionnaire}

The survey research design was utilised in this study. A questionnaire in two forms, one for the collegiate instrumental teachers, and another for the music performance undergraduate students was designed based on the research objectives to collect the data.

The questionnaire for the collegiate instrumental teachers was designed to i) collect the background information of the teachers (e.g., gender, nationality, teaching qualifications, years of teaching experience), ii) discover the number of complete semesters held between the participants, iii) estimate the students' practice habits in the practice room based on their performance during the instrumental lesson, iv) rate teachers' own ability to estimate their students' practice habits in the practice room, and v) give suggestions on how to estimate the students' practice habits in the practice room during the instrumental lessons. The questionnaire was presented in English.

At the same time, the questionnaire for the music performance undergraduate students was designed to i) collect the background information of the students (e.g., gender, nationality, academic years in music performance undergraduate program), ii) self-report their practice habits during the practice sessions in the previous week, and iii) obtain students' perceptions of their teachers' ability to estimate their practice habits. This questionnaire was presented in English and Thai, in which the Thai version was translated by a Ph.D. music education student who plays flute as her major instrument, to help the Thai undergraduate students to understand the questions better.

Development and validation of the questionnaire. To examine the first research objective, practice habits that were suitable for the music performance undergraduate students were listed by the researcher. Then, only those practice habits that were believed able to be observed through the students' performances by the instrumental teachers during the lessons were selected, categorised, and turned into questions (see Table 2) during the discussions between the researcher and the major advisor. Besides this, for the second research objective, open-ended questions in the teachers' questionnaire were designed to give suggestions on how they know whether their students i) set goals, ii) stayed focused on their playing, iii) practised the repertoire mentally, iv) applied the practice techniques, v) practised with a metronome, vi) practised with an electronic tuner, during the practice sessions between lessons, and to provide other suggestions to estimate students' practice habits in the practice room. After the proposal defence and the approval of the Institutional Review Board (IRB), the questionnaires for the collegiate instrumental teachers (in English) and music performance undergraduate students (in English and Thai) were sent to three experts for content verification. An index of Item-Objective Congruence (IOC) was used to evaluate the questions in both questionnaires based on the score ranging from +1 to -1 . The questions that scored an average of lower than 0.5 were revised, the questions that scored an average of higher than 0.5 were either revised or not revised based on the suggestions of the major advisor, and the questions that scored 1 remained unchanged. After that, a pre-test was conducted among three collegiate instrumental teachers and students from the same college to evaluate the clarity of each question in the questionnaire. Appropriate modifications were made based on the comments given.

Scores assignment. Scores were assigned to the survey questions related to the students' practice habits. Scores 1 to 3 for the students' days of practice in the previous week ( $1=1-2$ days, $2=3$ 5 days, $3=6-7$ days), scores 1 to 5 for the students' average of practice time per day in the previous week (1=0-60 minutes, $2=61-120$ minutes, $3=121-180$ minutes, $4=181-240$ minutes, $5=241$ minutes and above), scores 1 to 2 on whether having a practice session just before the lesson (1=Yes, $2=$ No), and scores 1 to 5 for the 21 five-point Likert-type scale questions about goal setting, focused attention, mental practice, technique practice, metronome practice, practise with an electronic tuner, and practise with other related practice strategies ( $1=$ Never, $2=$ Rarely, $3=$ Sometimes, $4=$ Almost always, $5=$ Always). 


\section{Data Collection and Data Analysis}

The data was collected during the sixth week of the second academic semester of 2018/2019 after the participants agreed to participate. Paper questionnaires were given to the participants after their instrumental lesson was over. All the participants had to fill in and return the questionnaire in an enclosed envelope within a week. Then, the answers in Thai language were translated by the same Ph.D. music education student who translated the Thai questionnaire.

After the data has been collected, the researcher applied the percentage (\%) to analyse the demographic data of both participants, to discover the number of complete semesters held between the participants, and to explore participants' perceptions of the teacher's ability to estimate the student's practice habits during the weekly instrumental lessons. Then, the percent agreement $\left(\mathrm{P}_{\mathrm{A}}\right)$ and Cohen's kappa ( $\kappa$, lower-case Greek letter) were utilised to examine the inter-rater reliability, which is, the extent of agreement, between the estimation data of collegiate instrumental teachers and self-report data of music performance undergraduate students on the 24 survey questions that are related to the practice habits. Also, collegiate instrumental teachers' suggestions on estimating students' practice habits in the practice room during the weekly instrumental lessons were summarised accordingly.

Percent agreement $\left(\mathbf{P}_{\mathrm{A}}\right) . \mathrm{P}_{\mathrm{A}}$ was used to assess how well two groups of participants identify a variable or set of variables. It will be reported in percentage $(\%)$ with the formula below.

$$
P_{A}=\frac{\text { Number of Agreement Responses }}{\text { Total Number of Responses }} \times 100
$$

Cohen's kappa ( $\kappa)$. Although $\mathrm{P}_{\mathrm{A}}$ provides the measure of agreement, it does not take into account the agreement that would be expected purely by chance. Thus, $K$ is here to consider the chance agreement and to calculate the 'true' agreement between the data. The formula for $\kappa$ was stated below, where $\operatorname{Pr}(a)$ represents the actual observed agreement and $\operatorname{Pr}(e)$ represents the chance agreement.

$$
\kappa=\frac{\operatorname{Pr}(a)-\operatorname{Pr}(e)}{1-\operatorname{Pr}(e)}
$$

According to McHugh (2012), the results of $\kappa$ can be range from -1 to +1 , where $\kappa=1$ represents complete or perfect agreement between the teachers and students, $\kappa=0$ represents the amount of agreement between the teachers and students that can be expected from random chance, and $\kappa=-1$ represents no effective agreement or disagreement between the teachers and students, or the agreement is worse than expected. This disagreement data is more like random data than properly collected research data which is unlikely in practice.

After the kappa value has been obtained, 95\% confidence interval (CI) was calculated to clarify whether the kappa result of each variable is reliable as it was gained from the rater's estimation or guessing. The formula for the $95 \%$ CI was stated below where 1.96 represents the value of the desired confidence interval level, and $\mathrm{SE}_{\mathrm{K}}$ represents the standard error of kappa.

$$
\mathrm{CI}=\kappa-1.96 \times \mathrm{SE}_{\mathrm{K}} \text { to } \kappa+1.96 \times \mathrm{SE}_{\mathrm{K}}
$$


Table 1

Interpretation of the Cohen's kappa (McHugh, 2012)

\begin{tabular}{|c|c|c|}
\hline Value of Kappa & Level of Agreement & \% of Data that are Reliable \\
\hline $0-.20$ & None Agreement & $0-4 \%$ \\
\hline $.21-.39$ & Minimal Agreement & $4-15 \%$ \\
\hline $.40-.59$ & Weak Agreement & $15-35 \%$ \\
\hline $.60-.79$ & Moderate Agreement & $35-63 \%$ \\
\hline $.80-.90$ & Strong Agreement & $64-81 \%$ \\
\hline Above .90 & Almost Perfect Agreement & $82-100 \%$ \\
\hline
\end{tabular}

\section{Results}

Two research questions were formed based on the research objectives:

First research question: Are the collegiate instrumental teachers able to estimate their students' practice habits in the practice room based on the students' performance during the instrumental lesson? Twenty-four survey questions that are related to the students' practice habits were designed to examine the first research question (see Table 2). Collegiate instrumental teachers were requested to estimate how their students practised in the previous week based on the students' performance during the lesson and music performance undergraduate students were required to self-report their practice habits in the previous week.

Table 2

The results of the percent agreement $\left(\mathrm{P}_{\mathrm{A}}\right)$, Cohen's kappa $(\kappa)$, 95\% confidence interval of the kappa value $(\mathrm{CI})$ and the level of agreement between the collegiate instrumental teachers and music performance undergraduate students on the students' practice habit questions

\begin{tabular}{|c|c|c|c|c|c|}
\hline Categories & Practice Habit Questions & $\mathbf{P}_{\mathrm{A}}$ & $\kappa$ & CI & $\begin{array}{c}\text { Level of } \\
\text { Agreement }\end{array}$ \\
\hline \multirow{2}{*}{ Practice Time } & $\begin{array}{l}\text { My student/I practised how many day(s) in } \\
\text { the previous week }\end{array}$ & $55.17 \%$ & .164 & -.1735 to .5015 & None \\
\hline & $\begin{array}{l}\text { My student/I spent an average of how } \\
\text { many minutes per day in the previous week }\end{array}$ & $21.43 \%$ & -.0441 & -.246 to .1578 & Disagreement \\
\hline Practice Session & $\begin{array}{l}\text { My student/I had/not had a practice session } \\
\text { just before the lesson }\end{array}$ & $50 \%$ & 0 & -.3702 to .3702 & None \\
\hline \multirow{3}{*}{ Goal Setting } & $\begin{array}{l}\text { My student/I set weekly goals for the } \\
\text { practice }\end{array}$ & $51.72 \%$ & .2495 & -.0331 to .5321 & Minimal \\
\hline & $\begin{array}{l}\text { My student/I set specific goals for each } \\
\text { practice session }\end{array}$ & $31.03 \%$ & .06 & -.1693 to .2893 & None \\
\hline & $\begin{array}{l}\text { My student/I kept a record of the practicing } \\
\text { goals }\end{array}$ & $25.93 \%$ & .0254 & -.192 to .2428 & None \\
\hline \multirow{3}{*}{$\begin{array}{l}\text { Focused } \\
\text { Attention }\end{array}$} & $\begin{array}{l}\text { My student/I stayed focus on what was } \\
\text { being practised until the goal had been } \\
\text { achieved }\end{array}$ & $43.33 \%$ & .1994 & -.0509 to .4497 & None \\
\hline & $\begin{array}{l}\text { My student/I paid attention to the sound } \\
\text { while playing }\end{array}$ & $30 \%$ & .014 & -.2171 to .2451 & None \\
\hline & $\begin{array}{l}\text { My student/I tried to avoid distraction } \\
\text { while practising }\end{array}$ & $51.72 \%$ & .2852 & .0157 to .5547 & Minimal \\
\hline Mental Practice & $\begin{array}{l}\text { My student/I 'mentally went through' the } \\
\text { music before playing it }\end{array}$ & $20.69 \%$ & -.0106 & -.1986 to .1774 & Disagreement \\
\hline
\end{tabular}




\begin{tabular}{|c|c|c|c|c|c|}
\hline & $\begin{array}{l}\text { My student/I sang important parts during } \\
\text { the practice session }\end{array}$ & $20 \%$ & -.0682 & -.2593 to .1229 & Disagreement \\
\hline \multirow{5}{*}{$\begin{array}{l}\text { Technique } \\
\text { Practice }\end{array}$} & $\begin{array}{l}\text { My student/I identified mistakes } \\
\text { immediately when they arose }\end{array}$ & $31.03 \%$ & .0252 & -.2124 to .2628 & None \\
\hline & $\begin{array}{l}\text { My student/I practised slowly during error } \\
\text { correction for accuracy }\end{array}$ & $20 \%$ & -.2141 & -.4315 to .0033 & Disagreement \\
\hline & $\begin{array}{l}\text { My student/I practised difficult spots in } \\
\text { isolation }\end{array}$ & $30 \%$ & -.0606 & -.3093 to .1881 & Disagreement \\
\hline & $\begin{array}{l}\text { My student/ I repeated difficult sections } \\
\text { until they had been mastered }\end{array}$ & $23.33 \%$ & -.1076 & -.3259 to .1107 & Disagreement \\
\hline & $\begin{array}{l}\text { My student/I varied the rhythms to practise } \\
\text { the difficult passagework }\end{array}$ & $23.33 \%$ & .0099 & -.1851 to .2049 & None \\
\hline \multirow{3}{*}{$\begin{array}{l}\text { Metronome } \\
\text { Practice }\end{array}$} & $\begin{array}{l}\text { My student/I used the metronome for slow } \\
\text { practice }\end{array}$ & $23.33 \%$ & .0129 & -.1821 to .2079 & None \\
\hline & $\begin{array}{l}\text { My student/I used the metronome to } \\
\text { increase the speed up to performance } \\
\text { tempo }\end{array}$ & $10 \%$ & -.1096 & -.2425 to .0233 & Disagreement \\
\hline & $\begin{array}{l}\text { My student/I used the metronome } \\
\text { throughout the whole piece }\end{array}$ & $33.33 \%$ & .1177 & -.1057 to .3411 & None \\
\hline \multirow{2}{*}{$\begin{array}{l}\text { Practise with an } \\
\text { Electronic } \\
\text { Tuner }\end{array}$} & $\begin{array}{l}\text { My student/I used the electronic tuner } \\
\text { during the practice }\end{array}$ & $20.69 \%$ & -.0706 & -.2696 to .1284 & Disagreement \\
\hline & $\begin{array}{l}\text { My student/ I used the electronic tuner for } \\
\text { drone effect }\end{array}$ & $43.33 \%$ & .2376 & -.0009 to .4761 & Minimal \\
\hline \multirow{3}{*}{ Others } & $\begin{array}{l}\text { My student/I recorded own playing for } \\
\text { self-reflection }\end{array}$ & $40 \%$ & .1497 & -.099 to .3984 & None \\
\hline & $\begin{array}{l}\text { My student/I listened to recordings of } \\
\text { pieces that he/she is or I am learning }\end{array}$ & $26.67 \%$ & .0922 & -.1038 to .2882 & None \\
\hline & $\begin{array}{l}\text { My student/I performed the whole piece as } \\
\text { part of the practice session }\end{array}$ & $30 \%$ & .0922 & -.1207 to .3051 & None \\
\hline
\end{tabular}

All collegiate instrumental teachers in this study agreed (86.67\%) and strongly agreed (13.33\%) that they could estimate their students' practice habits in the practice room during the weekly instrumental lessons and $70 \%$ of the music performance undergraduate students (with $30 \%$ of them stayed neutral) agreed (53.33\%) and strongly agreed (16.67\%) with their teachers' ability to do so. Further, students' perception about their teachers' ability were elaborated in words. One of the students stated, "When mistakes occur during the performance, my teacher will know immediately that I was just playing through the whole piece without stopping to correct my mistakes while practising". Another three students stated, "I seldom practise with the metronome. Therefore, when I struggled with the steady tempo, my teacher would notice that I did not practise with the metronome", "My teacher knew how well I prepared my songs by listening to the clarity of the notes, the fluency of the music, and the quality of my performance", and "My teacher knew my problems although I did not tell him. He could tell what I was thinking in the class. I think it's because what or how I practised was shown through my performance in the lesson".

However, the results obtained from the percent agreement $\left(\mathrm{P}_{\mathrm{A}}\right)$ and Cohen's kappa $(\kappa)$ reported that collegiate instrumental teachers could not effectively estimate their music performance undergraduate students' practice habits in the practice room based on the students' performance during the instrumental lesson. Overall, $\mathrm{P}_{\mathrm{A}}$ demonstrated a middle to a low percentage of agreement between the estimation data of the collegiate instrumental teachers and self-report data of the music performance undergraduate students, which at the same time, indicated a middle to a high percentage of erroneous agreement. The highest $\mathrm{P}_{\mathrm{A}}$ scored between the collegiate instrumental teachers and their students was $55.17 \%$, on the question, my student/I practised how many day(s) in the previous week, with $44.83 \%$ of incorrect data. Next, two questions: my student/I set weekly goals for the practice and my student/I tried to avoid distraction while practising, showed $51.72 \%$ of agreement and $48.28 \%$ of irrelevant agreement, and the question, my student/I had/not had a practice session just before the lesson, demonstrated $50 \%$ of agreement and erroneous agreement at the same time. Then, the rest of the 
questions (20 of them) scored lower than $50 \%$ of agreement, which indicated an erroneous agreement that is higher than $50 \%$. There is a $43.33 \%$ of agreement on two questions: my student/I stayed focus on what was being practised until the goal had been achieved and my student/I used the electronic tuner for drone effect; $40 \%$ of agreement on my student/I recorded own playing for self-reflection; $30 \%$ to $33.33 \%$ of agreement on six questions, listed from a higher to lower agreement score: my student/I used the metronome throughout the whole piece, my student/I identified mistakes immediately when they arose, my student/I set specific goals for each practice session, my student/I paid attention to the sound while playing, my student/I practised difficult spots in isolation, and my student/I performed the whole piece as part of the practice session; and $20 \%$ to $26.67 \%$ of agreement on 10 questions, again, in order from high to low: my student/I listened to recordings of pieces that he/she is or I am learning, my student/I kept a record of the practicing goals, my student/I repeated difficult sections until they were mastered, my student/I varied the rhythms to practise the difficult passagework, my student/I used the metronome for slow practice, my student/I spent an average of how many minutes per day in the previous week, my student/I 'mentally went through' the music before playing it, my student/I used the electronic tuner during the practice, my student/I sang important parts during the practice session, and my student/I practised slowly during error correction for accuracy (see Table 2). Lastly, the question, my student/I used the metronome to increase the speed up to the performance tempo showed the lowest $\mathrm{P}_{\mathrm{A}}$ score, which was only $10 \%$ of agreement, with a great amount of misrepresenting data (90\%) at the same time. The low $\mathrm{P}_{\mathrm{A}}$ score obtained from the estimation data of the collegiate instrumental teachers and self-report data of the music performance undergraduate students on the 24 practice habit questions, with an overall mean of $31.50 \%$, concluded that the collegiate instrumental teachers cannot effectively estimate their music performance undergraduate students' practice habits in the practice room based on the students' performance during the instrumental lesson.

On the other hand, Cohen's kappa $(\kappa)$ was used to calculate the possibility of the chance or random agreement. Among the 24 questions, $K$ results showed minimal agreement $(.21-.39)$ on three questions $(12.5 \%)$, none agreement $(0-.20)$ on 13 questions $(54.17 \%)$, and disagreement $(<0)$ on eight questions (33.33\%), which involved the three lowest levels of agreement on the interpretation of $\kappa$ (see Table 1 and 2). According to McHugh (2012), "Any kappa below .60 indicates inadequate agreement among the raters and little confidence should be placed in the study results" (p. 279). Also, "For kappa values below zero, although unlikely to occur in research data, when this outcome does occur it is an indicator of a serious problem" (p. 279). Based on the statements above, all the $\kappa$ results in this study was unsatisfied as none of them was above .60, with eight of them showing negative values. Although McHugh (2012) did mention that the kappa statistic will lower the estimation of agreement very much and it is common for the researchers to accept low kappa values in their inter-rater reliability study, but, the kappa values obtained in this study is way too low, with an overall mean score of .0437 among the 24 practice habit questions. In conclusion, the collegiate instrumental teachers cannot effectively estimate their music performance undergraduate students' practice habits in the practice room based on the students' performance during the instrumental lesson. All the results of $\kappa$ are reliable under the verification of the $95 \%$ confidence interval (CI) (see Table 2).

Second research question: What are the collegiate instrumental teachers' suggestions on estimating students' practice habits in the practice room? In this study, all the collegiate instrumental teachers were requested to give suggestions on how they know whether their students, i) set goals, ii) stayed focused on their playing, iii) practised the repertoire mentally, iv) applied the practice techniques, v) practised with a metronome, vi) practised with an electronic tuner, during the practice sessions based on their observations during the instrumental lessons. Besides this, teachers could include other suggestions that they would like to share at the end of the questionnaire. However, the suggestions given by the teachers were not only based on the observations but also, the communication between the teachers and students during the lessons. A summary of the suggestions given by the teachers were discussed accordingly.

Collegiate instrumental teachers assumed that their students had set goals for the practice sessions when they improved on performing difficult passages or when they improved from the previous lessons. One teacher stated, "When my student plays difficult spot considerably better than the previous week, I assume that she set some goals during her practice sessions". Besides this, teachers assume that their students had set goals when they completed the assignments given. "I will give my student 
assignments and see whether he completes it", mentioned by one of the teachers. Also, many suggestions related to the communication or discussion between the teachers and students during the lessons were given. For example, "I asked my student what he had practised in the past week", "I usually ask my student to give me a summary of what we had discussed last week and what she needs to prepare from the last lesson", and "We set goals in the class together and I will observe the results in the next lesson", suggested by some of the teachers. Besides, one teacher said he will set long-term goals for the students at the beginning of the semester and the students will decide the progress at their own pace. If his students are making good progress week by week, then he knows they have set short-term goals before reaching the long one.

Collegiate instrumental teachers knew their students stayed focused during the practice sessions when they performed better or improved after the previous lessons. One teacher said, "Focused practice leads to greater results. If there are better results or outcomes, I assume that the student had spent quality time during the practice sessions". Another teacher mentioned, "When my students do not repeat the same mistakes, I assumed that they stayed focused during their practice". Besides this, teachers made assumptions based on the students' personality. One teacher stated, "I know my student's character and the ability to concentrate at work. Also, I can see the result in the next lesson". Another teacher mentioned, "I can guess from the students' personalities. If the student is very focused during the lessons, I think he/she will be focused on his/her practice as well".

Students were assumed to practise mentally during the practice sessions when they performed their music musically with nice phrasing. One teacher commented, "I can see it when my student shows phrasing, directions, tempo changes, or new ideas confidently during the performance". Another teacher stated, "When my student plays the music smoothly, but not mechanically or in a choppy way". Besides this, teachers assume students had mentally practised when they were able to perform with accurate intonation and good memorisation, and when they can sing through the music while playing.

Instead of guessing what practice techniques that the students applied in the practice room, collegiate instrumental teachers in this study felt that increasing students' knowledge of practice techniques was more important. "Introducing students to 'how to practice' is a core component of most lessons", quoted by one of the teachers. Teachers believed that when the 'tools' in the students' practice toolbox is filled, they would naturally know which practice technique is suitable for specific improvement. One of the teachers said:

I spent the first year of lessons providing the students 'tools' for their practice toolbox. Students were reminded to use it regularly. Also, I suggested the students on how to improve the problematic passages. The improvement would show if those suggestions were followed accordingly.

Besides that, teachers would also determine students' use of practice techniques by asking the students how they practised during the practice sessions. One teacher said, "I will ask my student to give me a detailed description of what she had worked on since her last lesson and why". In addition, teachers could estimate students' use of practice techniques through the observations of the performance. "When a student can play some passages with different tempi, dynamics, articulation, and is able to transpose the passage to different keys, it shows that his/her practice method is flexible", or "When a student can perform the running notes evenly, it shows that he/she did some slow practice or practise with varied rhythms", mentioned by two teachers.

Teachers thought that students' habits of using a metronome during the practice could be seen obviously. When the students could keep the tempo throughout the music, keep the tempo and rhythm accurately with or without the metronome, aware of the unstable tempo, and were able to maintain the tempo and coordination between hands accurately, they were considered to be practising with a metronome.

To know whether the students have practised with an electronic tuner, collegiate instrumental teachers can observe through students' awareness of intonation and the ability to fix the tune correctly. One teacher stated, "I can see when my student played the song in tune and is able to adjust the tune if it is not correct". However, this practice habit was not suggested by most of the teachers in this study. One of the teachers commented that the flexibility of the intonation was more important as intonation problems might arose during the ensemble playing if the students practised with an electronic tuner frequently. Besides this, some string teachers in this study preferred their students to use their ears 
(listening to the music) instead of their eyes (looking at the cue of the electronic tuner) to control or adjust the intonation while playing, and an electronic tuner would be used only when they tune their instruments. This statement was supported by Millican (2011) in the article 'Turn Off the Tuner for Better Ensemble Intonation'. Millican (2011) thought that ensemble intonation will be accurate if the players turn off the tuner and tune the pitches with each other. He also stated that one who always relies on the cue of the tuner or conductor signals (visual reference) will not be able to adjust the pitch during the performances.

Other suggestions were shared by the collegiate instrumental teachers. One of the teachers mentioned:

It is dangerous to judge students' practice hours and methods solely based on their performance. In lessons, teachers should have frequent conversations with their students, encourage them to have concrete ideas about the music they play, let them express the ideas in words, and try to find the best way of practising together.

Besides this, "When the students performed confidently, it shows that some practices were done", "Keeping a lesson record tracker every week will improve the teachers' ability to estimate students' practice habits", "Teacher's teaching experience and the time spent with a student will give a strong indication of the student's practice habits", and "Know your student well. The better you know your student, the easier it is to determine his/her practice quality" were suggested by some of the teachers in this study.

\section{Discussion}

Although two-thirds (ten) of the collegiate instrumental teachers in this study are experienced teachers who have more than 10 years of teaching experience at the university level and a total of $76.67 \%$ of the music performance undergraduate students have considerable instrumental lesson experience with their teachers ranging from 2-11 complete semesters (with some of the students started the instrumental lessons with their teachers since they were studied at the Pre-College Program before they pursuing their undergraduate degree) that would help the teachers to understand the students better, negative results were still obtained.

This might be because collegiate instrumental teachers in this study think that communication between the teachers and students is as important as the observation of the students' performance during the instrumental lessons in terms of practice habits. Therefore, negative results were obtained when the teachers were instructed not to communicate with their students aurally about how they practise in the practice room and all the judgments were based on the observation of the students' performance. Besides this, the negative results might be influenced by other factors such as:

i) Lack of importance in this topic. No previous literature has been found to assist teachers on estimating students' practice habits in the practice room during the instrumental lessons.

ii) Lack of teachers' training. The highest qualification obtained by the collegiate instrumental teachers in this study mainly focused on the performance, performance and pedagogy, and performance and chamber music. These programmes do not emphasise much on the subject of music education. Although most teachers learn to observe their students intuitively over time, not all of them are doing it accurately.

iii) The data that was reported by the music performance undergraduates might not aligned with what they exactly did in the practice room. This is supported by the results in the article entitled 'An Analysis of Practice Room Behaviour of College Music Students' by Geringer and Kostka (1984). Geringer and Kostka (1984) comparing the results obtained from the college music students' self-reports with the observations in the practice room. They found that the students' behaviours in the practice room were not the same as what was reported by the students as they tended to spend more time in non-performance activities and overrated their performance behaviours in the practice room. 


\section{Recommendation}

This is an introductory study on estimating students' practice habits in the practice room based on the students' performance during the weekly instrumental lessons. It was done in one-time survey research design, to limit participants due to the restricted availability. Therefore, it would be interesting if this topic can be examined in qualitative research design for a longer time frame; invite more experts to participate, i.e. competition judges, music examiners, or teachers with a good reputation, and make comparisons with non-experienced teachers; increase the number of participants; investigate the practice habits in different styles of music, e.g., jazz music or popular music; and use different performance settings for estimation, e.g., competitions, recitals, and auditions, in the future.

For future development, it would be beneficial if a system in either music pedagogy or music education programmes that teaches the key indicators of estimating students' practice habits can be developed. Also, a training package or method to observe students' use of practice habits in the practice room is recommended to develop for future teachers.

\section{References}

Barry, N. H., \& Hallam, S. (2002). Practice. In Parncutt, R. \& McPherson, G. E. (Eds.), The science and psychology of music performance: Creative strategies for teaching and learning (pp. 151-165). Oxford University Press.

Bujang, M. A., \& Baharum, N. (2017). Guidelines of the minimum sample size requirements for Cohen's kappa. Epidemiology Biostatistics and Public Health, 14(2), e12267-1-e12267-10. https://doi.org/10.2427/12267

Bynum, J. (2019). Productive practice habits. International Trombone Association Journal, 47(4), 32-34. Academic Search Complete. (Accession No. 139177185)

Conrad, C. (2012, May 10). Top ten clues your student hasn't practiced. https://blog.musicteachershelper.com/top-ten-clues-your-student-hasnt-practiced/

Duhigg, C. (2012). The power of habit: Why we do what we do in life and business. Random House.

Ericsson, K. A., Krampe, R. T., \& Tesch-Romer, C. (1993). The role of deliberate practice in the acquisition of expert performance. Psychological Review, 100(3), 363-406. https://doi.org/10.1037//0033295X.100.3.363

Geringer, J. M., \& Kostka, M. J. (1984). An analysis of practice room behaviour of college music students. Contributions to Music Education, 11(1), 24-27. https://www.jstor.org/stable/24127283

Johnson, D. (2009). More than just minutes: Using practice charts as tools for learning. Music Educator Journal, 95(3), 63-70. https://doi.org/10.1177/0027432108330675

Kostka, M. J. (2002). Practice expectations and attitudes: A survey of college-level music teachers and students. Journal of Research in Music Education, 50(2), 145-154. https://doi.org/10.2307/3345818

Madsen, C. K. (2004). A 30-year follow-up study of actual applied music practice versus estimated practice. Journal of Research in Music Education, 52(1), 77-88. https://doi.org/10.2307/3345526

McHugh, M. L. (2012, October 15). Interrater reliability: The Kappa statistic. https://www.researchgate.net/publication/232646799_Interrater_reliability_The_kappa_statistic

Miksza, P. (2007). Effective practice: An investigation of observed practice behaviors, self-reported practice habits, and the performance achievement of high school wind players. Journal of Research in Music Education, 55(4), 359-375. https://doi.org/10.1177/0022429408317513

Miksza, P., \& Tan, L. (2015). Predicting collegiate wind players' practice efficiency, flow, and self-efficacy for self-regulation: An exploratory study of relationships between teachers' instruction and students' practicing. Journal of Research in Music Education, 63(2), 162-179. https://doi.org/10.1177/0022429415583474

Millican, S. (2011). Turn off the tuner for better ensemble intonation. School Band \& Orchestra, 14(8), 34-40. Education Source. (Accession No. 66173462)

Mills, J. (2007). Instrumental teaching. Oxford University Press.

Neal, D. T., Wood, W., \& Quinn, J. M. (2006). Habits-A repeat performance. Current Directions in Psychological Science, 15(4), 198-202. https://doi.org/10.1111/j.1467-8721.2006.00435.x

Pike, P. D. (2014). Behind the practice room door: A case study of second-year piano majors. MTNA e-journal, 5(3), 11-23. (Accession No. 2014-07085)

Platz, F., Kopiez, R., Lehmann, A. C., \& Wolf, A. (2014). The influence of deliberate practice on musical achievement: A meta-analysis. Frontiers in Psychology, 5. https://doi.org/10.3389/fpsyg.2014.00646

Schuring, M. (2009). Practice. Oboe art and method (pp. 70-92). Oxford University Press. 
Scott, S. J. (2012). Rethinking the roles of assessment in music education. Music Educators Journal, 98(3), 3135. https://doi.org/10.1177/0027432111434742

\section{Biography}

Lau Chooi Wee is a candidate in Master of Arts (Music) from the College of Music, Mahidol University, Thailand. She has received a Bachelor of Music from the University Putra Malaysia. 